Seeking Security or Seeking Pleasure in Sexual Behavior? Examining How Individual Motives Shape Condom Use Attitudes

David L. Rodrigues and Diniz Lopes

Iscte-Instituto Universitário de Lisboa, CIS-Iscte, Lisbon, Portugal

Short title: Individual motives and condom use attitudes

Corresponding author:

David Rodrigues

Iscte-Instituto Universitário de Lisboa, CIS-Iscte. Av. das Forças Armadas, 1649-026 Lisboa, Portugal.

Email: dflrs@iscte-iul.pt

Authors' contributions: Study conception and design, material preparation, data collection and analysis were performed by DLR. The first draft of the manuscript was written by DLR, and all authors commented on previous versions of the manuscript. All authors read and approved the final manuscript.

Funding: Part of this work was funded by a grant awarded by Fundação para a Ciência e a Tecnologia to DLR (Ref.: 2020.00523.CEECIND). 


\begin{abstract}
Research has consistently shown that motives for security (i.e., prevention focus) or pleasure (i.e., promotion focus) determine risk perception and behaviors in several domains, including sexual health. We tested if being more focused on prevention or promotion was associated with condom use attitudes and if the perceived risk of HIV infection explained these associations. Participants $\left(N=405,61.7 \%\right.$ women; $\left.M_{\text {age }}=23.10, S D=5.06\right)$ took part in an online cross-sectional study. We found positive associations between both regulatory foci and condom use attitudes. Mediation analyses also showed that participants who were more focused on prevention perceived condoms as more reliable, attributed less stigma to condom use, and were less embarrassed about condom use negotiation. These associations were explained by the perception of less risk of HIV infection. Results also revealed a few associations with personality traits and moderations by age and gender. These findings highlight the importance of considering individual motives to gain an understanding of how the perceived risk of infection can shape sexual health decision-making.
\end{abstract}

Keywords: Regulatory focus, Perceived risk; Condom attitudes; Embarrassment, Stigma; STIs 


\section{Seeking Security or Seeking Pleasure in Sexual Behavior? Examining How Individual Motives Shape Condom Use Attitudes}

Sexually transmitted infections (STIs) remain a significant public health concern, such that incidence rates have been steadily increasing in recent years (Scott-Sheldon \& Chan, 2020). Portugal was no exception and was even among the European countries with the highest rates of new HIV diagnosis (ECDC, 2020a, 2020b). Even though consistent and efficient condom use are highly effective strategies to prevent STI acquisition (Crosby et al., 2012), many people still abstain from using condoms (Fetner et al., 2020; Holway \& Hernandez, 2018; Nasrullah et al., 2017). Studies in Portugal have shown that condom use has been steadily decreasing among adolescents (Reis et al., 2018) and that neither condom use nor STI testing are widespread among Portuguese adults (Rodrigues et al., 2020).

Sexual behaviors and sexual health decisions are highly complex. Researchers are still discussing why some people use condoms and others forgo their use (de Visser \& O’Neill, 2013; Farrington et al., 2016; Glanz et al., 2015). People are more likely to make flawed sexual decisions (not using condoms) when they lack self-control (Magnusson et al., 2019) or when the sexual activity is unplanned (Elshiekh et al., 2020). In contrast, people tend to make health-protective decisions (using condoms) when they have more positive attitudes toward prevention (Reis et al., 2013) and perceive more health risks (Carvalho et al., 2015). These findings converge with research framed by the Regulatory Focus Theory (Higgins, 2015), showing that people who are motivated to maintain security (i.e., focused on prevention) tend to be more careful with their actions, whereas people motivated to seek pleasure (i.e., focused on promotion) tend to be more eager to pursue new opportunities. In the sexuality domain, people more focused on prevention strive to take fewer risks with their health (Rodrigues et al., 2020; Rodrigues, Lopes, \& Carvalho, 2021), whereas those more focused on promotion strive to attain sexual satisfaction (Evans-Paulson et al., 2021). However, no research to date 
has examined how and why having a focus on prevention or promotion shape attitudes toward condom use. To the extent that being motivated to think about a given object results in attitudes that are more predictive of behaviors (Glasman \& Albarracín, 2006), and that attitudes toward prevention increase condom adherence (Reis et al., 2013), people more focused on prevention (vs. promotion) should have more positive condom use attitudes. This association might be explained by the perceived risk of infection, given that risk awareness is particularly salient for people more focused on prevention (Rodrigues, Lopes, et al., 2019; Zou \& Scholer, 2016).

\section{Condom Use Attitudes}

Attitudes have long been considered one of the predictors of behavioral intentions and actual behaviors (Ajzen \& Fishbein, 2005; Glasman \& Albarracín, 2006), including condom use (Dolores Albarracín et al., 2001; Kiene et al., 2008; Sheeran et al., 1999). In their study, Elshiekh and colleagues (2020) found that positive views about condoms (i.e., perceiving condoms as protection against STI acquisition) help foster condom use, whereas negative views about condoms (i.e., perceiving condoms as decreasing sexual pleasure) help foster condomless sex. In another study, Guo and colleagues (2014) found that young adults with positive condom use attitudes had stronger intentions to use condoms, even when controlling for individual differences (e.g., knowledge about HIV) and demographic variables (e.g., gender). On the other hand, positive condom use attitudes increase the likelihood of using condoms more consistently and motivate people to develop preventive strategies. Research has shown that young adults with more positive condom use attitudes perceive greater severity in STI acquisition, are more likely to address safe sex practices with their partners, perceive more benefits in using condoms, are more likely to engage in preparatory behaviors (buying condoms), and have more self-control and self-efficacy over condom use (Carvalho et al., 2015; Montanaro \& Bryan, 2014; Reis et al., 2013). 
Among the different measures of condom use attitudes, the UCLA Multidimensional Condom Attitudes Scale (MCAS; Helweg-Larsen \& Collins, 1994) assesses five evaluative dimensions, namely perceptions of condoms as reliable and effective, sexual pleasure people have when using condoms, stigma associated with condom use, embarrassment about condom use negotiation, and embarrassment about condom purchase. Condom use attitudes can inform how people perceive, evaluate, and use condoms. Indeed, positive condom use attitudes - in all evaluative dimensions - have been linked to higher self-efficacy in condom use (González-Hernández et al., 2020). And yet, these dimensions are differently associated with sexual health behaviors. In their study, Plaza-Vidal and colleagues (2021) found that young adults who endorsed more sexual pleasure in condom use, less stigma about using condoms, and less embarrassment in condom negotiation were more assertive in their communication about condom use and had stronger condom use intentions. In another study, Maisto and colleagues (2004) found that young adults who endorsed more sexual pleasure in condom use had more skills to negotiate safe sex and weaker intentions to have risky sexual behaviors, regardless of other variables associated with sexual risk-taking (e.g., alcohol consumption; sensation seeking).

Attitudes are likely to be informed by exposure and personal experiences with the attitudinal object. Young adults with sexual experience have more positive attitudes toward condom use-endorsed more reliability and effectiveness to condoms, more sexual pleasure in condom use, and less embarrassment in condom negotiation and purchase-when compared to young adults without sexual experience (Choi et al., 2020). Attitudes are also amenable to change after intervention programs. People who received counseling sessions focused on HIV prevention reported more positive condom use attitudes and used condoms more consistently in the following three months (Rhodes et al., 2007), and adolescents reported increasingly positive condom use attitudes in all MCAS' evaluative dimensions after 
attending sexual education sessions over a 4-week period (Doubova et al., 2017). In these cases, the intervention protocols covered aspects about STI prevention and safer sex practices, arguably making people become more aware of health risks and motivating them to make healthier sexual decisions. To the extent that motivations are intrinsically correlated with attitudes (Glasman \& Albarracín, 2006) and that individual motives for security or pleasure favor distinct goal pursuit and behavioral decisions (Higgins, 2015), these motives can also inform and shape relevant attitudes.

\section{Regulatory Focus and Perceived Risk}

Regulatory Focus Theory (Higgins, 2015) posits that people regulate their feelings and actions under a prevention or promotion focus. People more focused on prevention are motivated by security maintenance, avoid taking risks, and experience negative affect by the anticipation losses. People more focused on promotion are motivated by pleasure-seeking, take more risks, and experience positive affect by anticipating gains (Higgins et al., 2001; Idson et al., 2000). These foci have clear implications for behavior across several domains. People more focused on prevention (vs. promotion) are less likely to take risks with their health and safety (Zou \& Scholer, 2016), including engaging in cancer screening procedures (Ferrer et al., 2017), maintaining smoking cessation after an intervention program (Fuglestad et al., 2013), retrieving health information form more credible sources (Rodrigues, 2021), and enacting preventive behaviors more frequently (Rodrigues, Lopes, \& Balzarini, 2021).

These findings are also extended to sexual behavior and sexual health. Indeed, young adults more focused on prevention tend to feel less safe having sex with casual partners, were more likely to have used condoms with casual partners, and believe they have more control over condom use, whereas those more focused on promotion report having used condoms less frequently with causal partners and got tested for STIs more often (Rodrigues et al., 2020; Rodrigues, Lopes, \& Carvalho, 2021). This seems to occur because health risks and 
threats are more salient in a prevention focus (Rodrigues, Lopes, et al., 2019) and sexual satisfaction is more salient under a promotion focus (Evans-Paulson et al., 2021).

To the extent that disregarding health risks can lead to flawed sexual decisions and adverse health outcomes (e.g., STI acquisition), being aware of threats and perceiving infection risks might be one of the mechanisms underlying the association between prevention (vs. promotion) focus and condom use attitudes. Indeed, risk perception has been associated with health behaviors, including condom use (or lack thereof). Young adults who perceive more risk of STI or HIV infection report more consistent condom use (Sacco et al., 1991) and have stronger intentions to discuss sexual health risks and condom use with their sex partners (Agocha \& Cooper, 1999), and have more positive condom use attitudes (Van Rossem \& Meekers, 2011). Moreover, young people were more likely to use condoms when they attended an intervention program focusing on risk perceptions (Mevissen et al., 2011), perceived invulnerability to HIV was undermined (Thompson et al., 2002), and suspected that their sex partner(s) acquired an STI (Crosby et al., 2014).

\section{Overview and Hypotheses}

Motivations and attitudes are intrinsically correlated (Glasman \& Albarracín, 2006) and motives for security and pleasure determine informing health-related goal pursuit (Zou \& Scholer, 2016). People more focused on prevention are more willing to enact sexual health behaviors, , whereas people more focused on promotion are more likely to pursue sexual satisfaction and take health risks (Evans-Paulson et al., 2021; Rodrigues, Lopes, et al., 2019; Rodrigues et al., 2020; Rodrigues, Lopes, \& Carvalho, 2021). However, research examining the role of regulatory focus in sexuality has mostly relied on a composite index instead of examining the unique contribution of prevention and promotion scores for sexual health behaviors. Moreover, the available evidence surrounding this construct is restricted to 
condom use and STI testing, and research is yet to determine how regulatory focus in sexuality is also associated with sexual health attitudes and through which mechanisms.

As prevention focus is linked to security motives in sex (Rodrigues, Lopes, et al., 2019; Zou \& Scholer, 2016), we expected people more focused on prevention to hold more positive condom use attitudes (H1a). In contrast, as promotion is linked to pleasure motives in sex (Evans-Paulson et al., 2021) and condoms are often perceived as barriers to pleasure (Randolph et al., 2007), we expected people more focused on promotion to hold more negative condom use attitudes $(\mathrm{H} 1 \mathrm{~b})$. We also expected these associations to be mediated by the perceived risk of HIV infection $(\mathrm{H} 2)$. To the extent that risk perception is associated with healthier sexual behaviors (Agocha \& Cooper, 1999; Crosby et al., 2014; Sacco et al., 1991; Van Rossem \& Meekers, 2011), people more focused on prevention (vs. promotion) should have more positive (vs. negative) condom use attitudes because they perceive more (vs. fewer) risks of HIV infection. We also explored if findings were consistent across all MCAS' evaluative dimensions.

We also examined the unique impact of regulatory focus on condom use attitudes controlling for personality traits, given that prevention and promotion foci have been associated with distinct personality traits (Liu \& Yao, 2019; Schmalbach et al., 2017; Vaughn et al., 2008). Hence, a more accurate understanding of how and why regulatory focus shapes sexual perceptions and behaviors must account for the role of personality. Lastly, to the extent that sexual attitudes and sexual behavior tend to differ according to demographic variables (e.g., age, gender, sexual orientation; Everett, 2013; Graf \& Patrick, 2014; Grollman, 2017; Mercer et al., 2013; Petersen \& Hyde, 2011; Rodrigues, Prada, et al., 2019), we explored these variables as possible moderators.

\section{METHOD}




\section{Participants and Procedure}

This study followed the guidelines of the Ethics Committee at [blinded for review]. Prospective participants were recruited through word of mouth and social media posts (e.g., Facebook), and invited to take part in an online survey about sexual behaviors. To be eligible, participants had to be at least 18 years of age, be currently single and not in a committed relationship, and have already engaged in sexual activity. No other inclusion/exclusion criteria were employed. After accessing the link provided in the advertisement, participants were informed of their rights (e.g., anonymous responses; possibility to omit any answer or withdraw from the study at any time without penalty) and that no compensation was offered upon survey completion. Participants had to provide informed consent before proceeding to the survey. The survey started with standard demographic questions (e.g., gender, age), followed by the main measures. Participants were reminded of any question left unanswered but were allowed to continue with the survey. In the end, participants were thanked and debriefed.

Of the 671 participants that accessed the survey, we removed participants who were in a relationship $(n=231)$ and those who had more than $10 \%$ missing data on our measures $(n=$ 35). This resulted in a sample size of 405 participants. As shown in Table 1, participants were, on average, 23 years old $(M=23.10, S D=5.06)$, and most were heterosexual $(91.3 \%)$ women $(61.7 \%)$ who were high-school graduates (51.9\%), lived in urban areas $(92.8 \%)$, were Catholics (47.4\%), and had no political orientation (49.1\%).

-- Table 1 --

\section{Measures}

\section{Regulatory Focus in Sexuality}

We used the 9-item scale developed by Rodrigues and colleagues (2019) to assess prevention focus (three items, $\alpha=.74$; e.g., "Not being careful enough in my sex life has 
gotten me into trouble at times", all reverse-coded) and promotion focus (six items, $\alpha=.82$; e.g., "I am typically striving to fulfill my desires with my sex life"). Responses were given in 7-point scales $(1=$ Not at all true of me to $7=$ Very true of me $)$. Items for each subscale were mean aggregated, with higher scores indicating a greater focus on prevention or promotion. Both subscales were negatively correlated, $p=.001$ (see Table 2 for details), but treated separately in our analyses.

\section{Perceived Risk of HIV}

We selected four items from the original scale developed by Napper and colleagues (2012). Based on the data provided in the Portuguese validation study (Martins et al., 2019), we selected the items with the highest factor loadings to assess perceived chances of infection (one item: "I think my chances of getting infected with HIV are...", $1=$ Zero to $7=$ Very large), vulnerability to infection (two items: "I worry about getting infected with HIV", $1=$ None of the time to $7=$ All of the time; "What is your gut feeling about how likely you are to get infected with HIV?", 1 = Extremely unlikely to 7 = Extremely likely), and salience of risk (one item: "Picturing myself getting HIV is something I find...", $1=$ Very hard to do to $7=$ Very easy to do). Items were mean aggregated $(\alpha=.70)$, with higher scores indicating a more perceived risk of infection.

\section{UCLA Multidimensional Condom Attitudes Scale (MCAS)}

We used the 25-item scale originally developed by Helweg-Larsen and Collins (Helweg-Larsen \& Collins, 1994) to assess condom use attitudes. This scale has five independent evaluative dimensions: (1) condom as reliable and effective (four items, e.g., "I think condoms are an excellent means of contraception"), (2) condom use as pleasurable (four items; e.g., "The use of condoms can make sex more stimulating”), (3) stigma associated with condoms (four items; e.g., "Women think men who use condoms are jerks"), (4) embarrassment about the negotiation and use of condoms (four items; e.g., "It is easy to 
suggest to my partner that we use a condom”), and (5) embarrassment about condom purchase (five items; e.g., "I always feel really uncomfortable when I buy condoms"). Responses were given in 7-point scales $(1=$ Strongly disagree to $7=$ Strongly agree $)$. After a preliminary analysis, we removed one item from the first dimension ("Condoms are an effective method of preventing the spread of AIDS and other sexually transmitted diseases") to increase reliability to acceptable levels. The resulting 24 -items were mean aggregated in each subscale, with scores indicating more confidence in condom use $(\alpha=.71)$, more pleasure when using condoms $(\alpha=.77)$, more stigma associated with condom use $(\alpha=.80)$, more embarrassment about condom use negotiation $(\alpha=.72)$, and more embarrassment about purchasing condoms $(\alpha=.89)$. All evaluative dimensions of the condom use attitudes scale were correlated in the expected direction, $p \mathrm{~s} \leq .010$ (see Table 2 for details).

\section{Big-Five Inventory-10}

We used the 10-item scale proposed by Rammstedt and John (2007) to assess extraversion (two items, Spearman's rho $=.46, p<.001$; e.g., "I see myself as someone who is outgoing, sociable"), agreeableness (two items, Spearman's rho $=.13, p=.009$; e.g., "I see myself as someone who is generally trusting"), conscientiousness (two items, Spearman's rho $=.15, p=.003$; e.g., "I see myself as someone who does a thorough job"), neuroticism (two items, Spearman's rho $=.39, p<.001$; e.g., "I see myself as someone who gets nervous easily"), and openness (two items, Spearman's rho $=.18, p<.001$; e.g., "I see myself as someone who has an active imagination"). Responses were given in 7-point scales $(1=$ Disagree strongly to $7=$ Agree strongly). Items were mean aggregated for each subscale, with higher scores indicating greater identification with the personality trait. Most subscales were correlated in the expected direction, $p s \leq .030$ (see Table 2 for details), albeit some nonsignificant correlations, $p \mathrm{~s} \geq .066$. 


\section{Analytic Plan}

We first computed overall correlations between all measures. Then, we used PROCESS 3.4 macro to test our main hypotheses and computed five mediation models with 10,000 bootstrap samples (Hayes, 2017). This macro allows estimating the unique contribution of multiple variables by entering additional predictor variables as covariates. Following our hypotheses, prevention and promotion scores were the predictor variables. Perceived risk of HIV infection was the mediation variable. Condom use attitudes were the different outcomes: perception of condoms as reliable (Model A), pleasure in condom use (Model B), stigma attributed to condom use (Model C), embarrassment about condom use negotiation (Model D), and embarrassment about condom purchase (Model E). We also conducted additional analyses controlling for personality traits as covariates.

Lastly, we explored if demographic variables moderated our findings. We began by examining correlations with age and testing for differences according to gender (women vs. men), sexual orientation (heterosexual vs. $\mathrm{LGB}+$ ), education level ( $\leq 12$ years vs. $>12$ years), residence (urban vs. rural area) using $t$-tests, and between religion and political orientation using MANOVAs with Bonferroni corrections. When significant correlations or differences were identified, we re-ran the models entering those variables as moderator variables.

\section{RESULTS}

\section{Preliminary Results}

Overall descriptive statistics and correlations between measures are presented in Table 2. Results showed that prevention scores were negatively associated with perceived risk of HIV infection, $p<.001$, stigma about condom use, $p=.001$, embarrassment about condom use negotiation, $p<.001$, embarrassment about condom purchase, $p=.019$, extraversion, $p=$ .005 , and neuroticism, $p=.021$. In contrast, prevention scores were positively associated with perceptions of condoms as reliable, $p=.012$, perceptions of condom use as pleasurable, $p=$ 
.006 , agreeableness, $p=.001$, and conscientiousness, $p=.009$. Promotion scores were positively associated with perceptions of condoms as reliable, $p=.048$, extraversion, $p<$ .001 , and openness, $p<.001$.

-- Table 2 --

\section{Main Analysis}

Results of the mediation analyses are summarized in Table 3. Direct effects showed that participants more focused on prevention perceived condoms as more reliable, $p=.049$ (Model A), had more pleasure using condoms, $p=.014$ (Model B), attributed less stigma to condom use, $p=.013$ (Model C), were less embarrassed about condom use negotiation, $p=$ .002 (Model D), and were less embarrassed about condom purchase, $p=.008$ (Model E). Similarly, participants more focused on promotion perceived condoms as more reliable, $p=$ .010 (Model A), and were less embarrassed about condom use negotiation, $p=.030$ (Model D). No other associations reached significance, $p \mathrm{~s} \geq .140$.

Despite these direct effects, results also showed that participants more focused on prevention perceived less risk of infection, $p<.001$, and in turn perceived condoms as more reliable, $p=.006$ (Model A), attributed less stigma to condom use, $p=.005$ (Model C), and were less embarrassed about condom use negotiation, $p=.002$ (Model D). Promotion scores were unrelated to risk perception, $p=.451$. In other words, some of the positive condom use attitudes reported by people more focused on prevention were, at least in part, explained by perceiving fewer risks.

-- Table 3 --

\section{Additional Analyses}

\section{Controlling for Personality Traits}

Results remained significant after controlling for personality traits, except for the positive association between prevention scores and perceptions of condoms as reliable, $p=$ 
.134 , and the positive association between promotion scores and embarrassment in condom negotiation, $p=.103$. There were also some associations worth noting. First, people who scored higher on agreeableness perceived less risk of HIV infection, $p=.005$. Second, there were a few direct associations between personality traits and condom use attitudes. People who scored higher on agreeableness attributed less stigma to condom use, $p=.003$, and were less embarrassed about condom negotiation, $p=.014$. People scoring higher on extraversion, $p=.004$, and openness, $p=.036$, were less embarrassed about condom purchase.

\section{Moderation by Demographic Variables}

Correlations with age showed that younger participants scored higher on prevention, $r(404)=-.18, p<.001$, whereas older participants perceived more risk of infection, $r(404)=$ $.12, p=.021$. No other correlations with age reached significance $p \mathrm{~s} \geq .105$. There were also a number of gender differences. Men perceived condoms as more reliable, $p=.017$, and attributed more stigma to condoms use, $p<.001$, whereas women had more pleasure using condoms, $p=.045$. No other differences emerged according to gender, $p \mathrm{~s} \geq .324$, sexual orientation, $p \mathrm{~s} \geq .064$, education level, $p \mathrm{~s} \geq .165$, residence, $p \mathrm{~s} \geq .141$, religion, multivariate $p$ $=.213$, or political orientation, multivariate $p=.052$.

To determine if age moderated any of our findings, we computed moderated mediation models probing for interactions in all paths using PROCESS (Hayes, 2017). Results showed mostly non-significant interactions with age, $p s \geq .075$, with one exception. Age moderated the association between prevention scores and condom reliability, $b=0.01, S E=.01, p=$ .015. Simple slopes revealed that older participants who were more (vs. less) focused on prevention perceived condoms as more reliable, $b=0.12, S E=.04, p=.004$, whereas no differences emerged for younger participants, $b=-0.01, S E=.05, p=.775$ (see Figure 1a). A floodlight analysis using the Johnson-Neyman technique (Spiller et al., 2013) revealed that the cut-off mean age for this significance was 24.15 years, $b=0.07, S E=.04, p=.050$. 
To determine if gender moderated any of our findings, we also computed moderated mediation models probing for interactions in all paths using PROCESS (Hayes, 2017). Results showed mostly non-significant interactions with age, $p \mathrm{~s} \geq .059$, with three exceptions. Specifically, gender moderated the associations between prevention scores and embarrassment about condom negotiation, $b=0.14, S E=.07, p=.043$, between promotion scores and stigma attributed to condom use, $b=-0.17, S E=.06, p=.007$, and between promotion scores and embarrassment about condom negotiation, $b=-0.21, S E=.09, p=$ .018. Simple slope analyses revealed that women more (vs. less) focused on prevention were less embarrassed about condom use negotiation, $b=-0.16, S E=.04, p<.001$, whereas no differences emerged for men, $b=-0.02, S E=.06, p=.767$ (see Figure 1b). In contrast, men more (vs. less) focused on promotion attributed less stigma to condom use, $b=-0.16, S E=$ $.05, p=.002$, whereas no differences emerged for women, $b=-0.02, S E=.06, p=.767$ (see

Figure 1c). Similarly, men more (vs. less) focused on promotion were less embarrassed about condom negotiation, $b=-0.24, S E=.08, p=.001$, whereas no differences emerged for women, $b=-0.03, S E=.05, p=.542$ (see Figure 1d).

-- Figure 1 ---

\section{DISCUSSION}

The Regulatory Focus Theory (Higgins, 2015) suggests that people pursue their goals by adopting a prevention or promotion focus. People more focused on prevention are motivated by security maintenance and tend to take fewer risks, whereas people more focused on promotion are motivated by pleasure and gratification and have greater risk propensity (Higgins et al., 2001; Idson et al., 2000). The importance of this motivation system for goal pursuit has also extended to the health domains (Ferrer et al., 2017; Fuglestad et al., 2013; Zou \& Scholer, 2016) and, more recently, to the sexual health domain (EvansPaulson et al., 2021; Rodrigues, Lopes, et al., 2019; Rodrigues et al., 2020; Rodrigues, Lopes, 
\& Carvalho, 2021). Building upon these recent findings, a cross-sectional study examined if being more focused on prevention or promotion was uniquely associated with condom use attitudes and whether the perceived risk of infection was one of the underlying mechanisms explaining these associations.

The results provided mixed support for our hypotheses. As expected, people more focused on prevention perceived condoms as more reliable, had more pleasure using condoms, attributed less stigma to condom use, were less embarrassed about condom use negotiation, and were less embarrassed about condom purchase. These results are aligned with the assumption that motivations are intrinsically related to attitudes (Glasman \& Albarracín, 2006). To the extent that security motives enhance protection goals and decrease risk-taking (Rodrigues, 2021; Rodrigues et al., 2020; Zou \& Scholer, 2016), people more focused on prevention feel more secure with condoms, have more positive views about condom use, are more comfortable taking control over condom use, and are more comfortable with buying condoms. Other theoretical models have already highlighted the importance of these variables (e.g., behavioral control; having preparatory behaviors) to predict condom use (Carvalho et al., 2015; de Visser \& O'Neill, 2013; Farrington et al., 2016; Glanz et al., 2015; Reis et al., 2013).

Contrary to our expectations, however, people more focused on prevention perceived less risk of HIV infection, which contributed to explaining why they also perceived condoms as more reliable, attributed less stigma to condom use, and were less embarrassed about condom use negotiation. Although unexpected, these findings make sense if we consider that having a prevention focus motivates people to enact health-protective behaviors over time (Fuglestad et al., 2013; Rodrigues, Lopes, \& Balzarini, 2021). By having more behavioral control in risky situations and by striving to maintain a course of action that favors their sexual health (Evans-Paulson et al., 2021; Rodrigues et al., 2020; Rodrigues, Lopes, \& 
Carvalho, 2021), these people perceive themselves as being at lower risk of STI acquisition and have less embarrassment with condom use negotiation and purchase. Note, however, that risk perception does not equate to perceiving less threat, such that people more focused on prevention are more aware of health threats (Rodrigues, Lopes, et al., 2019) and feel less safe with their casual partners (Rodrigues et al., 2020).

We also expected promotion focus to be negatively associated with condom use attitudes. However, people more focused on promotion perceived condoms as more reliable and were less embarrassed about condom use negotiation. This was somewhat surprising given people more focused on promotion are driven by pleasure (Higgins, 2015) and report more sexual satisfaction (Evans-Paulson et al., 2021), even though condoms are often considered a barrier to pleasure. Indeed, Randolph and colleagues (2007) found that people have more pleasurable intercourse when they have condomless sex, and those who perceive that using condoms cause a substantial decrease in their pleasure were less likely to have used condoms in the last three months. A careful analysis of our findings suggests that people more focused on promotion recognize the benefits of condom use to sexual health, are comfortable discussing condom use with their partners, and are arguably knowledgeable about sexual health. And yet, these people are more likely to make flawed sexual health decisions at the risk of acquiring STIs (Rodrigues et al., 2020; Rodrigues, Lopes, \& Carvalho, 2021). Furthermore, we found that promotion scores were unrelated to the perceived risk of infection. As such, the sexual health decision-making process for these people is not necessarily informed by their attitudes or explained by risk awareness, but arguably by the benefits of having more pleasurable sexual encounters (Evans-Paulson et al., 2021).

Examining the associations between regulatory focus and personality, we found that people more focused on prevention scored lower on extraversion and neuroticism and higher on agreeableness and conscientiousness. People more focused on promotion scored higher on 
extraversion and openness. Most of these associations had already been reported in the literature (Liu \& Yao, 2019; Schmalbach et al., 2017; Vaughn et al., 2008). We also found that agreeableness was negatively associated with perceived risk of infection, stigma attributed to condom use, and embarrassment about condom use negotiation. Both extraversion and openness were negatively associated with embarrassment about condom purchase. Despite these associations, however, most of our findings remained significant after controlling personality, indicating that regulatory focus was uniquely and distinctively associated with sexual health perceptions and attitudes.

There were also several differences according to demographic variables. We found that younger people were more focused on prevention and older people perceived more risk of infection. Also, women and men endorsed different condom use attitudes. Even though neither age nor gender emerged as moderators in our mediation models, both variables moderated different associations between regulatory focus and condom use attitudes. First, older people ( $>24$ years) more focused on prevention perceived condoms as more reliable. Assuming that older people have greater experience with condom use, being focused on prevention could benefit their decision-making process by improving their views about the effectiveness of condoms. Second, women more focused on prevention were less embarrassed about condom use negotiation. In contrast, men more focused on promotion were less embarrassed about condom use negotiation and attributed less stigma to condom use. These findings suggest that regulatory focus on sexuality operates differently for women and men. For women, being focused on sexual security could benefit their decision-making process by making them more comfortable discussing condom use with their casual partners (and arguably greater control over condom use). For men, it seems that being focused on sexual pleasure could benefit their decision-making process by decreasing the stigma associated with condom use and making them more comfortable discussing condom use. 
Although noteworthy, these findings were only observed on certain condom use attitudes, are highly exploratory, and should be taken with caution.

\section{Limitations and Future Studies}

Some limitations to this study must be acknowledged. Although our rationale followed a specific theoretical framework, we cannot determine causality between our variables given the cross-sectional nature of our data. Indeed, people more focused on prevention can have positive condom use attitudes because of risk awareness, but they can also perceive fewer risks because they have more positive condom use attitudes. Also, generalizations to the population must be taken with caution despite our demographically diverse sample of participants. Future studies should employ longitudinal designs with representative samples to replicate our findings and extend knowledge by including other evaluative dimensions of condom use (e.g., barriers and motivations; Golub \& Gamarel, 2017; Hill et al., 2011; Reece et al., 2010), by considering different protective functions of condoms (e.g., protection against unplanned pregnancies vs. STI prevention; Cooper et al., 1999; Elshiekh et al., 2020), or by examining if the effects of regulatory focus carry over to actual sexual health behaviors over time. Future studies should also expand the notion of risk of infection and include different STIs, account for the psychological, physical, and financial burden of acquiring different STIs (e.g., HIV vs. chlamydia), and examine trade-offs between security motives, pleasure motives, and risk-taking in distinct outcome scenarios. Given that people more focused on prevention report having more pleasure in using condoms, it would be interesting to examine if using condoms more frequently with casual partners is indeed a source of sexual pleasure or instead decreases sexual pleasure over time. In contrast, people more focused on promotion may be more likely to risk their health in the pursuit of sexual pleasure, especially if they identify a low (vs. high) risk of acquiring a severe STI. In this line of reasoning, given that people more focused on promotion also reported certain positive 
condom use attitudes, it would be interesting to examine why are these people more likely to make flawed sexual decisions despite their attitudes, or under which conditions are they likely to (at least momentarily) change their typical sexual health behaviors (e.g., receiving a positive STI diagnosis).

\section{Conclusion}

This study adds to a long-lasting discussion about the determinants of sexual health behaviors, by showing that individual motives for security or pleasure are associated with positive attitudes condom use attitudes. And yet, only prevention focus seems to inform the perception of health risks. These results show the importance of considering the motivational system to gain an understanding of sexual health decision-making. Specifically, our findings can help inform the development of more efficient awareness campaigns or intervention programs that are tailored to each regulatory focus. Research has shown that health campaigns have more impact when the tone of the message fits the regulatory focus of the person (Uskul et al., 2008). Hence, sexual health campaigns or programs that include messages and information using security and pleasure perspectives would likely have a stronger impact on the way people process and engage with the message. Consequently, people would likely be more engaged with the message, increase their sexual education, protect themselves and their partners from threats, and improve their overall well-being.

\section{Declarations}

Funding: Part of this work was funded by a grant awarded by [blinded for review] to [blinded for review] (Ref.: [blinded for review]).

Conflicts of interest/Competing interests: The authors have no relevant financial or nonfinancial interests to disclose.

Availability of data and material: The datasets generated during and/or analyzed during the current study are available from the corresponding author on reasonable request. 
Ethics approval: All procedures performed in studies involving human participants were in accordance with the ethical guidelines issued by the Ethics Committee of [blinded for review], and with the 1964 Helsinki declaration and its later amendments or comparable ethical standards.

Consent to participate: Informed consent was obtained from all participants included in the study.

\section{REFERENCES}

Agocha, V. B., \& Cooper, M. L. (1999). Risk perceptions and safer-sex intentions: Does a partner's physical attractiveness undermine the use of risk-relevant information? Personality and Social Psychology Bulletin, 25(6), 746-759. https://doi.org/10.1177/0146167299025006009

Ajzen, I., \& Fishbein, M. (2005). The influence of attitudes on behavior. In D. Albarracín, B. Johnson, \& M. Zanna (Eds.), The handbook of attitudes (pp. 173-221). Erlbaum.

Albarracín, D., Johnson, B. T., Fishbein, M., \& Muellerleile, P. A. (2001). Theories of Reasoned Action and Planned Behavior as models of condom use: A meta-analysis. Psychological Bulletin, 127(1), 142-161.

Carvalho, T., Alvarez, M.-J., Barz, M., \& Schwarzer, R. (2015). Preparatory behavior for condom use among heterosexual young men: A longitudinal mediation model. Health Education \& Behavior, 42(1), 92-99. https://doi.org/10.1177/1090198114537066

Choi, E. P. H., Fong, D. Y. T., \& Wong, J. Y. H. (2020). The use of the Multidimensional Condom Attitude Scale in Chinese young adults. Health and Quality of Life Outcomes, 18(1), 331. https://doi.org/10.1186/s12955-020-01577-9

Cooper, M. L., Agocha, V. B., \& Powers, A. M. (1999). Motivations for condom use: Do pregnancy prevention goals undermine disease prevention among heterosexual young 
adults? Health Psychology, 18(5), 464-474. https://doi.org/10.1037/02786133.18.5.464

Crosby, R. A., Charnigo, R. A., Weathers, C., Caliendo, A. M., \& Shrier, L. A. (2012). Condom effectiveness against non-viral sexually transmitted infections: A prospective study using electronic daily diaries. Sexually Transmitted Infections, 88(7), 484-489. https://doi.org/10.1136/sextrans-2012-050618

Crosby, R. A., Milhausen, R. R., Graham, C. A., Yarber, W. L., Sanders, S. A., Charnigo, R., \& Shrier, L. A. (2014). Likelihood of condom use when sexually transmitted diseases are suspected: Results from a clinic sample. Health Education \& Behavior, 41(4), 449-454. https://doi.org/10.1177/1090198114529588

de Visser, R. O., \& O’Neill, N. (2013). Identifying and understanding barriers to sexually transmissible infection testing among young people. Sexual Health, 10(6), 553-558. https://doi.org/10.1071/SH13034

Doubova, S. V., Martinez-Vega, I. P., Infante-Castañeda, C., \& Pérez-Cuevas, R. (2017). Effects of an internet-based educational intervention to prevent high-risk sexual behavior in Mexican adolescents. Health Education Research, 32(6), 487-498. https://doi.org/10.1093/her/cyx074

ECDC. (2020a). Annual epidemiological report for 2018. ECDC.

ECDC. (2020b). HIV/AIDS surveillance in Europe 2020 (2019 data). ECDC. https://www.ecdc.europa.eu/en/publications-data/hivaids-surveillance-europe-20202019-data

Elshiekh, H. F., Hoving, C., \& de Vries, H. (2020). Exploring determinants of condom use among university students in Sudan. Archives of Sexual Behavior, 49(4), 1379-1391. https://doi.org/10.1007/s10508-019-01564-2 
Evans-Paulson, R., Widman, L., Javidi, H., \& Lipsey, N. (2021). Is regulatory focus related to condom use, STI/HIV testing, and sexual satisfaction? The Journal of Sex Research, Advance online publication. https://doi.org/10.1080/00224499.2021.1961671

Everett, B. G. (2013). Sexual orientation disparities in sexually transmitted infections: Examining the intersection between sexual identity and sexual behavior. Archives of Sexual Behavior, 42(2), 225-236. https://doi.org/10.1007/s10508-012-9902-1

Farrington, E. M., Bell, D. C., \& DiBacco, A. E. (2016). Reasons people give for using (or not using) condoms. AIDS and Behavior, 20(12), 2850-2862. https://doi.org/10.1007/s10461-016-1352-7

Ferrer, R. A., Lipkus, I. M., Cerully, J. L., McBride, C. M., Shepperd, J. A., \& Klein, W. M. P. (2017). Developing a scale to assess health regulatory focus. Social Science \& Medicine, 195, 50-60. https://doi.org/10.1016/j.socscimed.2017.10.029

Fetner, T., Dion, M., Heath, M., Andrejek, N., Newell, S. L., \& Stick, M. (2020). Condom use in penile-vaginal intercourse among Canadian adults: Results from the sex in Canada survey. PLoS ONE, 15(2), e0228981. https://doi.org/10.1371/journal.pone.0228981

Fuglestad, P. T., Rothman, A. J., \& Jeffery, R. W. (2013). The effects of regulatory focus on responding to and avoiding slips in a longitudinal study of smoking cessation. Basic and Applied Social Psychology, 35(5), 426-435. https://doi.org/10.1080/01973533.2013.823619

Glanz, K., Rimer, B. K., \& Viswanath, K. (Eds.). (2015). Health behavior and health education: Theory, research, and practice (5th ed.). Jossey-Bass. 
Glasman, L. R., \& Albarracín, D. (2006). Forming attitudes that predict future behavior: A meta-analysis of the attitude-behavior relation. Psychological Bulletin, 132(5), 778822. https://doi.org/10.1037/0033-2909.132.5.778

Golub, S. A., \& Gamarel, K. E. (2017). Psychometric evaluation of the Condom Barriers and Motivations Scale (CBMS). Journal of Behavioral Medicine, 40(3), 494-505. https://doi.org/10.1007/s10865-016-9815-x

González-Hernández, A. M., Escobar-Estupinan, J. L., \& Vallejo-Medina, P. (2020). Condom use errors and problems in a sample of young Colombian adults. The Journal of Sex Research, 57(9), 1217-1224. https://doi.org/10.1080/00224499.2020.1728207

Graf, A. S., \& Patrick, J. H. (2014). The influence of sexual attitudes on mid-to late-life sexual well-being: Age, not gender, as a salient factor. The International Journal of Aging and Human Development, 79(1), 55-79. https://doi.org/10.2190/AG.79.1.c

Grollman, E. A. (2017). Sexual orientation differences in attitudes about sexuality, race, and gender. Social Science Research, 61, 126-141.

https://doi.org/10.1016/j.ssresearch.2016.05.002

Guo, R., McAleese, W. J., Appleby, K. M., Guo, J., Zhang, W., Huang, Y., \& Peterson, T. (2014). Predictors of intention to use condoms among Chinese college students. Journal of Community Health, 39(4), 712-718. https://doi.org/10.1007/s10900-0139816-4

Helweg-Larsen, M., \& Collins, B. E. (1994). The UCLA Multidimensional Condom Attitudes Scale: Documenting the complex determinants of condom use in college students. Health Psychology, 13, 224-237. https://doi.org/10.1037/02786133.13.3.224 
Higgins, E. T. (2015). Regulatory Focus Theory. In R. A. Scott, M. C. Buchmann, \& S. M. Kosslyn (Eds.), Emerging trends in the social and behavioral sciences: An Interdisciplinary, searchable, and linkable resource (pp. 1-18). Wiley. https://doi.org/10.1002/9781118900772.etrds0279

Higgins, E. T., Friedman, R. S., Harlow, R. E., Idson, L. C., Ayduk, O. N., \& Taylor, A. (2001). Achievement orientations from subjective histories of success: Promotion pride versus prevention pride. European Journal of Social Psychology, 31(1), 3-23. https://doi.org/10.1002/ejsp.27

Hill, B. J., Amick, E. E., \& Sanders, S. A. (2011). Condoms and US college-aged men and women: Briefly assessing attitudes toward condoms and general condom use behaviours. Sexual Health, 8(3), 372-377. https://doi.org/10.1071/SH10058

Holway, G. V., \& Hernandez, S. M. (2018). Oral sex and condom use in a U.S. national sample of adolescents and young adults. Journal of Adolescent Health, 62(4), 402410. https://doi.org/10.1016/j.jadohealth.2017.08.022

Idson, L. C., Liberman, N., \& Higgins, E. T. (2000). Distinguishing gains from nonlosses and losses from nongains: A regulatory focus perspective on hedonic intensity. Journal of Experimental Social Psychology, 36(3), 252-274.

https://doi.org/10.1006/jesp.1999.1402

Kiene, S. M., Tennen, H., \& Armeli, S. (2008). Today I'll use a condom, but who knows about tomorrow: A daily process study of variability in predictors of condom use. Health Psychology, 27(4), 463-472. https://doi.org/10.1037/0278-6133.27.4.463

Liu, H., \& Yao, M. (2019). Regulatory focus profiles among Chinese pre-adolescents and adolescents and their relationship to personality and psychological outcomes. Journal of Happiness Studies, 20(6), 1807-1824. https://doi.org/10.1007/s10902-018-0025-9 
Magnusson, B. M., Crandall, A., \& Evans, K. (2019). Early sexual debut and risky sex in young adults: The role of low self-control. BMC Public Health, 19(1), 1483. https://doi.org/10.1186/s12889-019-7734-9

Maisto, S. A., Carey, M. P., Carey, K. B., Gordon, C. M., Schum, J. L., \& Lynch, K. G. (2004). The Relationship between alcohol and individual differences variables on attitudes and behavioral skills relevant to sexual health among heterosexual young adult men. Archives of Sexual Behavior, 33(6), 571-584.

https://doi.org/10.1023/B:ASEB.0000044741.09127.e6

Martins, A., Chaves, C., Canavarro, M. C., \& Pereira, M. (2019). Psychometric properties of the European Portuguese version of the Perceived Risk of HIV Scale in the general population and HIV-uninfected partners from sero-different couples. BMC Public Health, 19(1), 1336. https://doi.org/10.1186/s12889-019-7696-y

Mercer, C. H., Tanton, C., Prah, P., Erens, B., Sonnenberg, P., Clifton, S., Macdowall, W., Lewis, R., Field, N., Datta, J., Copas, A. J., Phelps, A., Wellings, K., \& Johnson, A. M. (2013). Changes in sexual attitudes and lifestyles in Britain through the life course and over time: Findings from the National Surveys of Sexual Attitudes and Lifestyles (Natsal). The Lancet, 382(9907), 1781-1794. https://doi.org/10.1016/S0140$6736(13) 62035-8$

Mevissen, F. E. F., Ruiter, R. A. C., Meertens, R. M., Zimbile, F., \& Schaalma, H. P. (2011). Justify your love: Testing an online STI-risk communication intervention designed to promote condom use and STI-testing. Psychology \& Health, 26(2), 205-221. https://doi.org/10.1080/08870446.2011.531575

Montanaro, E. A., \& Bryan, A. D. (2014). Comparing theory-based condom interventions: Health Belief Model versus Theory of Planned Behavior. Health Psychology, 33(10), 1251-1260. https://doi.org/10.1037/a0033969 
Napper, L. E., Fisher, D. G., \& Reynolds, G. L. (2012). Development of the Perceived Risk of HIV scale. AIDS and Behavior, 16(4), 1075-1083. https://doi.org/10.1007/s10461011-0003-2

Nasrullah, M., Oraka, E., Chavez, P. R., Johnson, C. H., \& DiNenno, E. (2017). Factors associated with condom use among sexually active US adults, National Survey of Family Growth, 2006-2010 and 2011-2013. The Journal of Sexual Medicine, 14(4), 541-550. https://doi.org/10.1016/j.jsxm.2017.02.015

Petersen, J. L., \& Hyde, J. S. (2011). Gender differences in sexual attitudes and behaviors: A review of meta-analytic results and large datasets. The Journal of Sex Research, 48(23), 149-165. https://doi.org/10.1080/00224499.2011.551851

Plaza-Vidal, R., Ibagon-Parra, M., \& Vallejo-Medina, P. (2021). Spanish translation, adaptation, and validation of the Multidimensional Condom Attitudes Scale with young Colombian men and women. Archives of Sexual Behavior, 50(6), 2729-2740. https://doi.org/10.1007/s10508-020-01759-y

Rammstedt, B., \& John, O. P. (2007). Measuring personality in one minute or less: A 10-item short version of the Big Five Inventory in English and German. Journal of Research in Personality, 41(1), 203-212. https://doi.org/10.1016/j.jrp.2006.02.001

Randolph, M. E., Pinkerton, S. D., Bogart, L. M., Cecil, H., \& Abramson, P. R. (2007). Sexual pleasure and condom use. Archives of Sexual Behavior, 36(6), 844-848. https://doi.org/10.1007/s10508-007-9213-0

Reece, M., Herbenick, D., Hollub, A. V., Hensel, D. J., \& Middlestadt, S. E. (2010). A psychometric assessment of the Multi-Factor Attitude Toward Condoms Scale (MFACS). International Journal of Sexual Health, 22(2), 119-129. https://doi.org/10.1080/19317610903526097 
Reis, M., Ramiro, L., Camacho, I., Tomé, G., \& Gaspar de Matos, M. (2018). Trends in Portuguese adolescents' sexual behavior from 2002 to 2014: HBSC Portuguese study. Portuguese Journal of Public Health, 36(1), 32-40. https://doi.org/10.1159/000486014

Reis, M., Ramiro, L., Matos, M. G. de, \& Diniz, J. A. (2013). Determinants influencing male condom use among university students in Portugal. International Journal of Sexual Health, 25(2), 115-127. https://doi.org/10.1080/19317611.2012.728554

Rhodes, F., Stein, J. A., Fishbein, M., Goldstein, R. B., \& Rotheram-Borus, M. J. (2007). Using theory to understand how interventions work: Project RESPECT, condom use, and the Integrative Model. AIDS and Behavior, 11(3), 393-407. https://doi.org/10.1007/s10461-007-9208-9

Rodrigues, D. L. (2021). Regulatory focus and perceived safety with casual partners: Implications for perceived risk and casual sex intentions during the COVID-19 pandemic. Psychology \& Sexuality, Advance online publication. https://doi.org/10.1080/19419899.2021.2018355

Rodrigues, D. L., Lopes, D., \& Balzarini, R. N. (2021). Having a prevention regulatory focus longitudinally predicts distress and health-protective behaviors during the COVID-19 pandemic. PsyArXiv. https://doi.org/10.31234/osf.io/k7j6h

Rodrigues, D. L., Lopes, D., \& Carvalho, A. C. (2021). Regulatory focus and sexual health: Motives for security and pleasure in sexuality are associated with distinct protective behaviors. The Journal of Sex Research, Advance online publication. https://doi.org/10.1080/00224499.2021.1926413

Rodrigues, D. L., Lopes, D., Pereira, M., Prada, M., \& Garrido, M. V. (2019). Motivations for sexual behavior and intentions to use condoms: Development of the Regulatory 
Focus in Sexuality scale. Archives of Sexual Behavior, 48(2), 557-575. https://doi.org/10.1007/s10508-018-1316-2

Rodrigues, D. L., Lopes, D., Pereira, M., Prada, M., \& Garrido, M. V. (2020). Predictors of condomless sex and sexual health behaviors in a sample of Portuguese single adults. The Journal of Sexual Medicine, 17(1), 26-36. https://doi.org/10.1016/j.jsxm.2019.10.005

Rodrigues, D. L., Prada, M., \& Lopes, D. (2019). Perceived sexual self-control and condom use with primary and casual sex partners: Age and relationship agreement differences in a Portuguese sample. Psychology \& Health, 34(10), 1231-1249. https://doi.org/10.1080/08870446.2019.1603384

Sacco, W. P., Levine, B., Reed, D. L., \& Thompson, K. (1991). Attitudes about condom use as an AIDS-relevant behavior: Their factor structure and relation to condom use. Psychological Assessment, 3(2), 265-272. https://doi.org/10.1037/1040-3590.3.2.265

Schmalbach, B., Zenger, M., Spina, R., Steffens-Guerra, I., Kliem, S., Michaelides, M., \& Hinz, A. (2017). Gain +1 or avoid -1: Validation of the German Regulatory Focus Questionnaire (RFQ). BMC Psychology, 5(1), 40. https://doi.org/10.1186/s40359017-0207-y

Scott-Sheldon, L. A. J., \& Chan, P. A. (2020). Increasing sexually transmitted infections in the U.S.: A call for action for research, clinical, and public health practice. Archives of Sexual Behavior, 49(1), 13-17. https://doi.org/10.1007/s10508-019-01584-y

Sheeran, P., Abraham, C., \& Orbell, S. (1999). Psychosocial correlates of heterosexual condom use: A meta-analysis. Psychological Bulletin, 125(1), 90-132.

Spiller, S. A., Fitzsimons, G. J., Lynch, J. G., \& McClelland, G. H. (2013). Spotlights, floodlights, and the magic number zero: Simple effects tests in moderated regression. Journal of Marketing Research, 50, 277-288. https://doi.org/10.1509/jmr.12.0420 
Thompson, S. C., Kyle, D., Swan, J., Thomas, C., \& Vrungos, S. (2002). Increasing condom use by undermining perceived invulnerability to HIV. AIDS Education and Prevention, 14(6), 505-514. https://doi.org/10.1521/aeap.14.8.505.24115

Uskul, A. K., Keller, J., \& Oyserman, D. (2008). Regulatory fit and health behavior. Psychology \& Health, 23(3), 327-346. https://doi.org/10.1080/14768320701360385

Van Rossem, R., \& Meekers, D. (2011). Perceived social approval and condom use with casual partners among youth in urban Cameroon. BMC Public Health, 11(1), 632. https://doi.org/10.1186/1471-2458-11-632

Vaughn, L. A., Baumann, J., \& Klemann, C. (2008). Openness to experience and regulatory focus: Evidence of motivation from fit. Journal of Research in Personality, 42(4), 886-894. https://doi.org/10.1016/j.jrp.2007.11.008

Zou, X., \& Scholer, A. A. (2016). Motivational affordance and risk-taking across decision domains. Personality and Social Psychology Bulletin, 42(3), 275-289. https://doi.org/10.1177/0146167215626706 
Individual motives and condom use attitudes

Table 1

Demographic Characteristics

\begin{tabular}{lcc}
\hline & $N$ & $M(S D)$ or \% \\
\hline Age & 405 & $23.10(5.06)$ \\
Gender & 250 & \\
$\quad$ Female & 155 & 61.7 \\
$\quad$ Male & & 38.3 \\
Sexual orientation & 367 & 64.9 \\
$\quad$ Heterosexual & 28 & 7.0 \\
$\quad$ Bisexual & 6 & 1.5 \\
$\quad$ Lesbian/gay & 1 & 0.2 \\
$\quad$ Pansexual & & \\
Education level & 10 & 2.6 \\
$\quad$ Less than 10 years & 211 & 51.9 \\
High school graduate & 138 & 34.0 \\
University graduate & 46 & 11.4 \\
$\quad$ Master or Doctoral degree & & \\
Residence & 376 & 92.8 \\
$\quad$ Urban areas & 29 & 7.2 \\
$\quad$ Rural areas & & \\
Religion & 192 & 47.4 \\
$\quad$ Catholic & 25 & 6.2 \\
Christian & 20 & 4.9 \\
Other religion & 168 & 41.5 \\
$\quad$ No religion & & \\
Political orientation & 60 & 14.8 \\
$\quad$ Right-wing & 46 & 11.4 \\
$\quad$ Center & 100 & 24.7 \\
$\quad$ Left-wing & 199 & 49.1 \\
$\quad$ No political orientation & & \\
\hline
\end{tabular}




\section{Table 3}

\section{Mediation Analyses}

$\mathrm{M}$

Condoms: Reliability

Condoms: Pleasure

Condoms: Stigma Embarrassment

$b(S E)$

$b(S E)$

$b(S E)$

$b(S E)$

negotiation

Condoms:

Predictors $-0.21^{* * *}(.03)$

$0.07^{*}(.04)$

$0.10^{*}(.04)$

$-0.06^{*}(.02)$

$b(S E)$

Prevention focus in sexuality (X1)
Promotion focus in sexuality (X2)

$0.11^{* *}(.04)$

$0.06(.05)$

$-0.06(.02)$

Perceived risk of HIV infection (M)

$-0.14^{* *}(.05)$

$-0.05(.06)$

$0.10^{* *}(.04)$

$-0.10^{* *}(.03)$

$-0.09^{*}(.05)$

$0.15^{* *}(.05)$

burchase

Indirect effects

$\quad b(\mathrm{SE})[95 \% \mathrm{CI}] \quad b(\mathrm{SE})[95 \% \mathrm{CI}]$

Prevention focus in sexuality

$.03(.01)$

$b(S E)[95 \% \mathrm{CI}] \quad b(S E)[95 \% \mathrm{CI}]$

b $b(S E)[95 \% \mathrm{CI}]$

Total effects
Prevention focus in sexuality $b(S E)[95 \% \mathrm{CI}]$ $b(\mathrm{SE})[95 \% \mathrm{CI}]$ $b(S E)[95 \% \mathrm{CI}]$

$-0.08(.02)[-0.13 ;-0.04]$

$-0.14(.03)[-0.20 ;-0.07]$ Embarrassment

Promotion focus in sexuality

$0.11(.04)[0.02 \cdot 0.20]$

$0.11(.04)[0.04 ; 0.19]$

$-0.03(.03)[-0.09 ; 0.03]$

$-0.09(.04)[-0.17 ;-0.00]$

$-0.12^{*}(.05)$

$-0.10(.06)$

$0.01(.08)$ Note Cov $=$ Covariate

${ }^{*} p \leq .050 .{ }^{* *} p \leq .010 .{ }^{* * *} p \leq .001$. 
Individual motives and condom use attitudes

Table 2

Overall Descriptive Statistics and Correlations

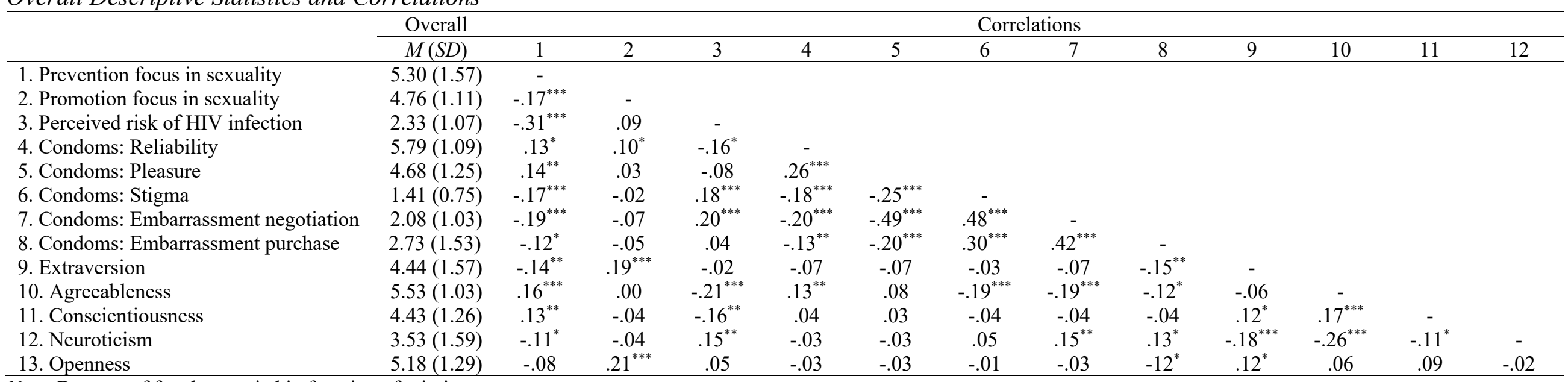

Note. Degrees of freedom varied in function of missing cases.

${ }^{*} p \leq .050 .{ }^{* *} p \leq .010 .{ }^{* * *} p \leq .001$. 
Individual motives and condom use attitudes

\section{Figure 1}

Interactions Between Regulatory Focus in Sexuality and Age and Gender
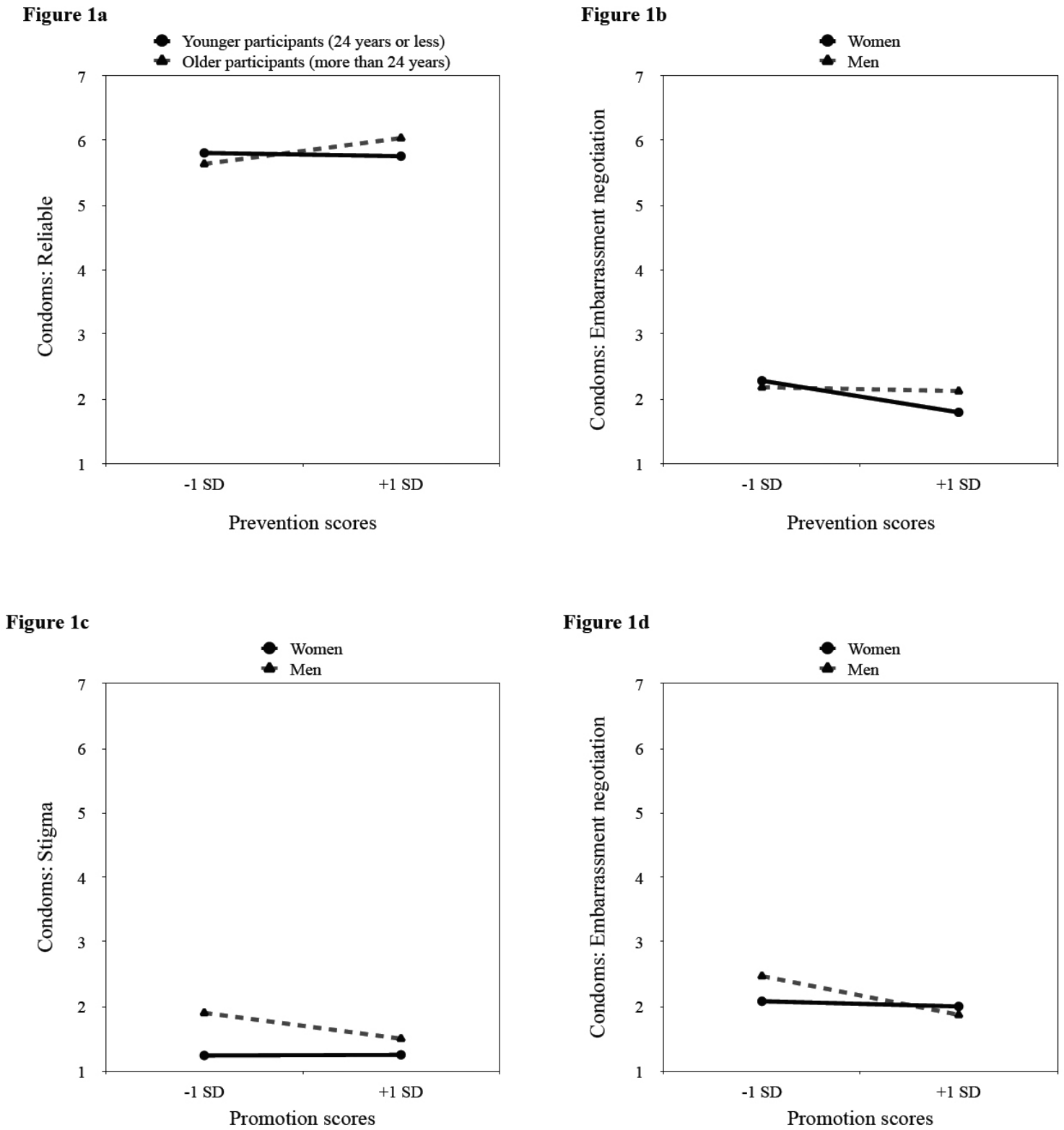